\title{
ESTUDO ECONÔMICO DE SISTEMAS FERTIRRIGADOS NA CULTURA DA BANANEIRA (Musa sp.), CULTIVAR WILLIANS ${ }^{1}$
}

\author{
ADRIANA NOVAIS MARTINS 2 , FERNANDA DE PAIVA BADIZ FURLANETO ${ }^{3}$, \\ NAÍSSA MARIA SILVESTRE DIAS ${ }^{4}$, EDUARDO SUGUINO 5
}

RESUMO- O Brasil ocupa a quarta posição no ranking dos países produtores de banana. O Estado de São Paulo é responsável por aproximadamente $17 \%$ da produção nacional. As áreas de produção de banana, antes restritas à faixa litorânea do Estado, estão expandindo-se e ocupando regiões do planalto paulista. Para atingir altas produtividades, com frutas de qualidade, os bananicultores estão adotando novas tecnologias, sendo que a fertirrigação vem ocupando lugar de destaque nos novos sistemas produtivos. Com o objetivo de avaliar a economicidade do uso do nutriente potássio em diferentes doses $\left(0 ; 300 ; 600\right.$ e $900 \mathrm{~kg} \mathrm{~K}_{2} \mathrm{O}_{\text {. ha-1 }}^{-1}$. $\mathrm{ano}^{-1}$ ) em plantio experimental, na região do Médio Paranapanema, Estado de São Paulo, foram estimados os valores do custo de produção e de indicadores econômicos, como o Custo Operacional Total (COT), a Receita Líquida e o Índice de Rentabilidade, de sistemas fertirrigados na cultura da bananeira. De acordo com a metodologia adotada, o uso do potássio, na dose de $900 \mathrm{~kg} \mathrm{de}_{2} \mathrm{O} \mathrm{ha}^{-1}$.ano ${ }^{-1}$, aplicado através de sistema de fertirrigação, pode ser recomendado para o plantio de bananeira, cultivar Willians, na região do Médio Paranapanema, Estado de São Paulo.

Termos para indexação: bananicultura, sistema de irrigação, potássio, custo de produção, rentabilidade.

\section{ECONOMIC STUDY OF FERTIRRIGATION SYSTEM IN BANANA CROP (Musa sp.), 'WILLIANS' CULTIVAR}

\begin{abstract}
Brazil is in the fourth ranking position in the banana producing countries. The state of Sao Paulo accounts for approximately $17 \%$ of the national production. The areas of banana production, but restricted to the coastal strip of the state, are expanding and occupying regions of the Sao Paulo plateau. To achieve high yields, with fruit quality of banana, growers are adopting new technologies and the fertirrigation has been occupying a prominent place in the new production systems. In order to assess the economic viability of the use of potassium in different doses $\left(0 ; 300 ; 600\right.$ e $\left.900 \mathrm{~kg} \mathrm{~K}_{2} \mathrm{O}^{-h^{-1}}{ }^{-a n o^{-1}}\right)$ in experimental planting in the Middle Paranapanema, in the state of São Paulo, were estimated values of the production cost and economic indicators, such as Total Operating Cost (TOC), Net Revenue and Profitability Index, of systems fertirrigated in the banana crop. According to the methodology, the use of potassium in dose of 900 $\mathrm{kg} \mathrm{K}_{2} \mathrm{O} \cdot \mathrm{ha}^{-1}$. ano ${ }^{-1}$, applied through fertirrigation system can be recommended for banana planting, 'Willians' cultivar, in the Middle Paranapanema, state of Sao Paulo.
\end{abstract}

Index terms: banana, irrigation system, potassium, cost of production, profitability.

\footnotetext{
${ }^{1}$ (Trabalho 263-09). Recebido em: 25-11-2009. Aceito para publicaçaõ em: 01-06-2010.

${ }^{2}$ Pesquisadora Científica, Dra., APTA Médio Paranapanema, Rodovia SP 333 (Assis-Marília) km 397, 19.802-970, Assis, São Paulo E.mail: adrianamartins@apta.sp.gov.br

${ }^{3}$ Pesquisadora Científica, M.Sc., APTA Centro Oeste, Marília-SP. E.mail: fernandafurlaneto@apta.sp.gov.br

${ }^{4}$ Programa de Pós Grduação, ESALQ/USP. Piracicaba-SP. E.mail: naissasilvestre@hotmail.com

${ }^{5}$ Pesquisador Científico, Dr., APTA Centro Leste, Ribeirão Preto-SP. E.mail: esuguino@apta.sp.gov.br
} 


\section{INTRODUÇ̃̃O}

A técnica de aplicação de fertilizantes por meio da irrigação (fertirrigação) otimiza o uso dos insumos uma vez que aumenta a eficiência da adubação, além de reduzir a mão de obra, o custo com máquinas e flexibiliza a época de aplicação, sendo que as doses recomendadas podem ser fracionadas de acordo com a demanda nutricional da cultura (MELO et al., 2009).

O nutriente mais importante na bananicultura é o potássio $(\mathrm{K})$, que corresponde a, aproximadamente, $62 \%$ do total de macronutrientes e $41 \%$ do total de nutrientes absorvidos pela planta. A função do potássio está relacionada à translocação dos fotossintatos e ao balanço hídrico da planta, além de ter grande importância na produção de frutos, aumentando a resistência ao transporte e melhorando a qualidade, uma vez que promove o aumento dos teores de sólidos solúveis totais e açúcares, com descréscimo da acidez da polpa (BORGES; OLIVEIRA, 2000; SATHIAMOORTHY; JEYABASKARAN, 2001).

Entre as principais fontes, o cloreto de potássio é o mais solúvel e utilizado, seguido pelo nitrato de potássio e pelo sulfato de potássio. As quantidades de potássio recomendadas nas regiões produtoras de banana no mundo oscilam de 228 a $1.600 \mathrm{~kg}$ de $\mathrm{K}_{2} \mathrm{O} \cdot \mathrm{ha}^{-1}$. ano ${ }^{-1}$. No Brasil, utilizando sistema de adubação convencional, ou seja, sem fertirrigação, essas doses variam de 0 a $750 \mathrm{~kg}$ de $\mathrm{K}_{2} \mathrm{O} \cdot \mathrm{ha}^{-1}$. ano $^{-1}$, dependendo dos teores do nutriente no solo. Entretanto, nas áreas irrigadas do norte de Minas Gerais, foram obtidas respostas significativas em lavouras que receberam até $1.600 \mathrm{~kg}$ de $\mathrm{K}_{2} \mathrm{O}$. ha $^{-1} \cdot$ ano $^{-1}$, porém deve-se considerar o preço de aquisição do insumo e da venda da fruta para avaliar a viabilidade econômica da utilização de elevadas doses de fertilizantes na bananicultura (BORGES; COSTA, 2002).

Vários trabalhos sobre nutrição de bananeiras foram realizados em cultivos comerciais (MAHALAKSHMI et al., 2003; GUERRA et al., 2004; PINTO et al., 2005; OLIVEIRA et al., 2005; DAMATTO JÚNIOR et al., 2006; TEIXEIRA et al., 2007; FREITAS et al., 2008), porém são escassas as informações econômicas disponíveis na literatura especializada sobre a utilização da fertirrigação em cultivos de bananeira (SANTANA et al., 2004; FURLANETO et al., 2007a). Nesse sentido, este artigo teve como objetivo avaliar a economicidade da fertilização de bananeiras, cultivar Willians, com diferentes doses de potássio, aplicadas via fertirrigação, na região do Médio Paranapanema, Estado de São Paulo.

\section{MATERIAL E MÉTODOS}

Os dados produtivos foram obtidos por meio da colheita de campo experimental fertirrigado de bananeiras da Agência Paulista de Tecnologia dos Agronegócios do Médio Paranapanema (APTA), instalado na Área Experimental Agroflorestal Sustentável, no município de Palmital, região do Médio Paranapanema, Estado de São Paulo, no espaçamento de 2,0 × 2,5 m, totalizando 2.000 plantas por hectare.

O Médio Paranapanema localiza-se na região sudoeste paulista. A caracterização pedológica mostra predomínio de Latossolos Vermelhos distroférricos (39\%) e Latossolos Vermelhos eutroférricos $(48 \%)$, sendo que o teor médio de potássio no solo (camada entre 0 e $20 \mathrm{~cm}$ ) é de $2,0 \mathrm{mmol} / \mathrm{dm}^{3}$, valor este encontrado em análise química do solo da área experimental, considerado um teor médio para a cultura da bananeira. O clima desta região é caracterizado como sendo do tipo Cfa, segundo a classificação de Köeppen, ou seja, moderadamente úmido, sem estação seca, com a precipitação do mês mais seco maior que $30 \mathrm{~mm}$, temperatura média do mês mais frio inferior a $18^{\circ} \mathrm{C}$, mas acima de $-3^{\circ} \mathrm{C}$, e a temperatura média do mês mais quente superior a $22^{\circ} \mathrm{C}$ (PRADO et al., 2003; ROLIM et al., 2007). A probabilidade de ocorrência de geadas é relativamente baixa - cerca de $30 \%$ dos anos (CAMARGO et al., 1993; PRELA-PANTANO et al., 2009). Essas características edafoclimáticas são favoráveis ao cultivo da bananeira na região.

Avaliou-se economicamente a utilização de três doses de potássio $\left(300 ; 600\right.$ e $900 \mathrm{~kg}$ de $\mathrm{K}_{2} \mathrm{O}$. ha $^{-1} \cdot$ ano $^{-1}$ ) em cultivo de bananeiras, cultivar Willians, em comparativo com cultivo efetuado na ausência desse nutriente, sendo o experimento caracterizado conforme demonstra a Tabela 1.

Utilizaram-se, no sistema de irrigação, microaspersores autocompensantes e lâmina de irrigação de 1,4 ETo (evapotranspiração de referência) monitorada através da instalação de tensiômetros na área. A produtividade do $1^{\circ}$ ciclo foi obtida no campo, e as produtividades do $2^{\circ}$ e $3^{\circ}$ ciclos foram estimadas de acordo com os percentuais referentes à colheita do $1^{\circ}$ ano produtivo (Tabela 1 ) devido ao tempo de instalação da lavoura ( 2 anos). O módulo mínimo considerado para a instalação de sistemas de fertirrigação foi de cinco hectares em decorrência do custo dos equipamentos por unidade de área, que é de, aproximadamente, $\mathrm{R} \$ 5.200,0$ por hectare. O 
custo com a manutenção e o reparo dos equipamentos foi estimado em $10 \%$ do valor total de instalação do sistema de fertirrigação ao mês, ou seja, R\$ 520,00.

A aplicação dos fertilizantes foi realizada com frequência semanal, distribuída durante todo o ano. $\mathrm{Na}$ implantação da cultura, foi realizada a aplicação de calcário dolomítico de acordo com resultados de análise de solo, de modo a elevar a saturação de bases a 70\%. Também foi feita a adubação fosfatada com a aplicação de superfosfato simples na cova, seguindo os resultados da análise de solo, de acordo com as recomendações técnicas para a cultura. Foram aplicados, via fertirrigação, nitrato de amônia em dose equivalente a $500 \mathrm{~kg} \mathrm{~N} \cdot$ ha $^{-1}$. ano $^{-1}$ e cloreto de potássio em doses equivalentes a 300; 600 e $900 \mathrm{~kg}$ de $\mathrm{K}_{2} \mathrm{O}$. $\mathrm{ha}^{-1}$. ano ${ }^{-1}$, em comparativo com área conduzida na ausência desse fertilizante.

Os valores econômicos foram levantados nos municípios de Palmital, Cândido Mota, Assis e Ourinhos, no período de julho a outubro de 2009. A cotação do dólar corresponde a $\mathrm{R} \$ 2,33$. A metodologia do cálculo de custo de produção utilizada foi a do Instituto de Economia Agrícola (IEA), descrita em Matsunaga et al. (1976). As estruturas consideradas no sistema produtivo foram: - Custo operacional efetivo (COE), que são as despesas efetuadas com mão de obra, operações de máquinas/equipamentos e materiais consumidos ao longo do processo produtivo; - Custo operacional total (COT), que é o custo operacional efetivo acrescido dos gastos com encargos sociais diretos $(33,0 \%$ sobre a mão de obra comum e do tratorista), contribuição de seguridade social rural $(2,2 \%$ sobre a receita bruta), encargos financeiros do capital de custeio $(8,75 \%$ a.a. sobre $50,0 \%$ do $\mathrm{COE})$, assistência técnica $(5,0 \%$ sobre o $\mathrm{COE})$ e depreciação de máquinas.

Os indicadores de análise de resultados de rentabilidade utilizados no trabalho foram os definidos em Martin et al. (1998):

a) Receita Bruta (RB): é a receita esperada para determinada produção por hectare, para um preço de venda predefinido, ou efetivamente recebido, ou seja:

$$
R B=\operatorname{Pr} x \operatorname{Pu}
$$

em que: $P r=$ produção da atividade por unidade de área;

$$
P u=\text { preço unitário do produto. }
$$

b) Lucro Operacional (LO) ou receita líquida (RL): constitui a diferença entre a receita bruta e o custo operacional por hectare. $\mathrm{O}$ indicador do resultado do lucro operacional mede a lucratividade da atividade no curto prazo, mostrando as condições financeiras e operacionais da atividade. Desse modo tem-se:

$$
L O=R B-C O T
$$

em que: $C O T=$ custo operacional total de produção.

c) Índice de Lucratividade (IL): esse indicador mostra a relação entre o lucro operacional e a receita bruta, em percentagem. É uma medida importante de rentabilidade da atividade agropecuária, uma vez que mostra a taxa disponível de receita da atividade após o pagamento de todos os custos operacionais. Então:

$$
\mathrm{IL}=(\mathrm{LO} / \mathrm{RB}) \times 100
$$

\section{RESULTADOS E DISCUSSÃO}

No manejo fertirrigado com ausência de aplicação de $\mathrm{K}_{2} \mathrm{O}\left(\mathrm{T}_{1}\right)$, o COT correspondeu a $\mathrm{R} \$$ 14.980,00.ha-1 (Ano de formação), R\$ 6.710,00.ha-1 ( $1^{\circ}$ ciclo), R\$ 7.158,00.ha -1 $^{\circ} 2^{\circ}$ ciclo) e R $\$ 7.168,00$. ha $^{-1}\left(3^{\circ}\right.$ ciclo). O elevado custo do ano de formação deve-se, principalmente, à aquisição das mudas micropropagadas e equipamentos de irrigação. Nos demais anos, o COT foi crescente devido ao acréscimo do custo com a colheita (operações mecanizadas, manuais e insumos). $\mathrm{O}$ custo médio por unidade de peso da fruta foi de $\mathrm{R} \$ 0,34 . \mathrm{kg}^{-1}$. A receita líquida e o índice de lucratividade foram positivos a partir do $2^{\circ}$ ciclo $\left(\mathrm{R} \$ 989,00 . \mathrm{ha}^{-1} \mathrm{e}\right.$ $8 \%$, respectivamente). A receita bruta acumulada mostrou-se favorável somente no $3^{\circ}$ ciclo (R\$ 1.821,00.ha ${ }^{-1}$ ), conforme demonstra a Tabela 2 .

Utilizando $300 \mathrm{~kg} \mathrm{~K}$ O.ha-1.ano-1 $\left(\mathrm{T}_{2}\right)$, o COT foi de $\mathrm{R} \$ 15.730,00 \cdot \mathrm{ha}^{-1}$ (Ano de formação). No $1^{\circ}, 2^{\circ}$ e $3^{\circ}$ ciclos, o COT correspondeu a R $\$ 7.521,00$, $\mathrm{R} \$ 7.989,00$ e $\mathrm{R} \$ 8.028,00 . \mathrm{ha}^{-1}$, respectivamente. A produtividade e o COT acumulado aumentaram em média 31 e 9\% em relação ao $\mathrm{T}_{1}$. O custo de produção médio estimado da caixa de $22 \mathrm{~kg}$ foi de $\mathrm{R} \$ 7,0\left(\mathrm{R} \$ 0,29 \cdot \mathrm{kg}^{-1}\right)$. A receita líquida e o índice de lucratividade apontaram que, no $\mathrm{T}_{2}$, a rentabilidade foi favorável a partir do $1^{\circ}$ ciclo de produção. Já a receita bruta acumulada foi positiva apenas no $4^{\circ}$ ciclo (Tabela 3 ).

No $\mathrm{T}_{3}\left(600 \mathrm{~kg}\right.$ de $\mathrm{K}_{2} \mathrm{O} \cdot \mathrm{ha}^{-1}$. ano $\left.{ }^{-1}\right)$, o COT acumulado foi $18 \%$ superior ao $\mathrm{T}_{1}$, porém a produtividade média foi superior em $50 \%$. O COT do ano de formação correspondeu a R \$ 16.479,00ha-1. Esse valor, para o $1^{\circ}, 2^{\circ}$ e $3^{\circ}$ ciclos, foi de $\mathrm{R} \$ 8.321,00, \mathrm{R} \$ 8.802,00$, $\mathrm{R} \$ 8.848,00 . \mathrm{ha}^{-1}$. O custo médio do quilo da fruta correspondeu a $\mathrm{R} \$ 0,27 . \mathrm{kg}^{-1}$. A receita líquida foi de R\$ 2.134,00, R\$ 5.145,00 e R\$ 7.079,00.ha-1. O índice médio de lucratividade estimado foi de $24 \%$ 
(Tabela 4).

Observou-se, no $\mathrm{T}_{4}\left(900 \mathrm{~kg}\right.$ de $\mathrm{K}_{2} \mathrm{O} \cdot \mathrm{ha}^{-1}$. ano $^{-1}$ ), um COT de R $\$ 16.880,00, \mathrm{R} \$ 8.709,00$, $\mathrm{R} \$ 9.098,0$ e $\mathrm{R} \$ 9.120,00 . \mathrm{ha}^{-1}$ para o ano de formação, $1^{\circ}, 2^{\circ}$ e $3^{\circ}$ ciclos, respectivamente. O COT acumulado foi $22 \%$ e a produtividade média $59 \%$ superior em relação ao $\mathrm{T}_{1}$. O custo da caixa de $22 \mathrm{~kg}$ foi de $\mathrm{R} \$ 6,00\left(\mathrm{R} \$ 0,26 \cdot \mathrm{kg}^{-1}\right)$. A receita líquida foi favorável desde o $1^{\circ}$ ciclo de produção. $\mathrm{O}$ índice de lucratividade médio correspondeu a $26 \%$. A receita bruta acumulada foi positiva a partir do $3^{\circ}$ ciclo produtivo (Tabela 5).

Santana et al. (2004) apresentaram os custos de instalação e manutenção de um hectare de bananeiras "Prata-Anã", em regime de irrigação por microaspersão, na região de Bom Jesus da LapaBA, considerando o espaçamento de 4,0 X 2,0 X 2,0 $\mathrm{m}$ e densidade de 1.600 plantas por hectare. No primeiro ano, os gastos com insumos representaram $83 \%$ do COE, sendo seguidos dos gastos com tratos culturais e fitossanitários $(6 \%)$, irrigação $(5 \%)$, preparo do solo e plantio (4\%) e colheita (1\%). No segundo ano, a participação percentual foi de $57 \%$ para os insumos, $32 \%$ para a colheita, $5 \%$ para tratos culturais, $5 \%$ para irrigação e $1 \%$ para o preparo do solo. Do terceiro ao sexto ano, o bananal apresentou produtividade estável de 40 t.ha ${ }^{-1} \mathrm{e}$ manteve a importância relativa dos custos semelhante em relação ao segundo ano. O COT foi de $\mathrm{R} \$ 8.401,00 . \mathrm{ha}^{-1}$ (Ano 1), R \$ 8.903,00.ha-1 (Ano 2) e R $\$ 9.909,00 \cdot$ ha $^{-1}$ (Anos 3-6). A produção da fruta mostrou-se rentável.

Furlaneto et al. (2007a) descreveram que, na região do Médio Paranapanema, no sistema de manejo irrigado, lavouras com banana, cultivar Grande Naine, produtividade no ano 2 de 50 t.ha $^{-1}$; no ano 3 de 59 tha $^{-1} \mathrm{e}$, nos anos de $4 \mathrm{e} 5 \mathrm{de} 63$ tha $^{-1}$; período anual médio de colheita de 11 meses; espaçamento médio de plantio de 2,0 X 2,5 m e 2.000 famílias.ha ${ }^{-1}$, o COT correspondeu a R \$ 15.075,00 na formação da lavoura, sendo que, nos anos de produção, esse custo ficou entre R\$ 7.500,00 e R \$ 7.800,00. $\mathrm{ha}^{-1}$, em valores correspondentes à safra de 2006/2007. Os insumos representaram $59 \%$, e as operações manuais, $16 \%$ do COT. O índice de lucratividade foi de 44\% (Anos 2 a 4) e 48\% (Ano 5). Esses valores foram semelhantes aos encontrados por Zonetti et al. (2002), em estudo econômico realizado com a cultivar Jangada, na região de Ilha Solteira, Estado de São Paulo.

Ainda na região do Médio Paranapanema, Furlaneto et al. (2007b) verificaram o custo de produção das cultivares de bananeiras do subgrupo Cavendish ('Grande Naine', 'Willians', 'Jangada') no sistema de plantio convencional, não irrigado. Foram considerados seis anos da lavoura. As mudas utilizadas para a implantação da lavoura foram mudas micropropagadas. $\mathrm{O}$ espaçamento de plantio foi de 2,0 × 2,5 m, resultando em 2.000 famílias.ha ${ }^{-1}$. As produtividades médias identificadas foram: ano 2 - 40 t.ha $^{-1}$, ano 3 - 45 t.ha ${ }^{-1}$ e anos 4-6 - 50 t.ha $^{-1}$. O período anual de colheita considerado foi de cerca de 10 meses. O COT de implantação e manutenção do bananal (Ano 1) foi de R $\$ 8.555,00 . \mathrm{ha}^{-1}$, Os gastos com materiais representaram $69 \%$ do montante. No ano 2, o COT correspondeu a $\mathrm{R} \$ 4.990,00$ e no ano $3 \mathrm{R} \$ 5.662,00$. A partir do ano 4, o COT atingiu R\$ $5.965,00 . \mathrm{ha}^{-1}$. As principais despesas foram com tratamento fitossanitário ( $29 \%$ do COT) e fertilizantes (18\%). A receita líquida obtida no ano 2 foi de $\mathrm{R} \$$ 3.810,00.ha ${ }^{-1}$, aumentando para $\mathrm{R} \$ 4.237,00 . \mathrm{ha}^{-1} \mathrm{e} \mathrm{R} \$$ $5.035,00$. ha $^{-1}$ nos anos subsequentes (Ano 3 e Ano 4). A partir do ano 4, o índice de lucratividade chegou a $46 \%$, evidenciando que a cultura proporciona ganhos expressivos ao produtor.

Araújo et al. (2008) analisaram o custo econômico de bananeiras, cultivar Pacovan, na região do Submédio São Francisco, sendo o sistema de produção em fileira dupla de 5,0 x 2,0 x 2,0 m, totalizando 1.428 plantas e produtividade de 30 t.ha $^{-1}$, sistema de irrigação por aspersão convencional e verificaram que o COT e a receita líquida média foram de $\mathrm{R} \$ 9.383,00 . \mathrm{ha}^{-1}$ e R $\$ 3.216,00 . \mathrm{ha}^{-1}$. ano ${ }^{-1}$, respectivamente.

De acordo com o Agrianual (2009), no ano de 2008, o custo operacional total de um bananal formado com plantas da variedade Nanica, no Vale do Ribeira, São Paulo, utilizando o espaçamento de 2,0 x 2,5 m, totalizando 2.000 famílias. ha ${ }^{-1}$, sem irrigação, com produtividade de $30 ; 35 ; 40 ; 45$ e 45 t.ha $^{-1}$, foi de R $\$ 16.747,00, \mathrm{R} \$ 9.106,00, \mathrm{R} \$ 9.756,00$ e R\$9.590,00.ha-1, respectivamente, para o ano 1 (formação), ano 2, ano 3 e anos 4 ao 5 . A receita líquida apresentou-se positiva somente a partir do $4^{\circ}$ ano, alcançando o valor de $\mathrm{R} \$ 9.171,00 \cdot \mathrm{ha}^{-1}$.

Já no ano de 2009, nessa mesma região e nas mesmas condições de plantio, o custo total de produção correspondeu a R $\$ 16.234,00$ (Ano 1), R\$ 8.041,00 (Ano 2), R\$ 8.721,00 (Ano 3) e R\$ 8.592,00.ha-1 (Anos 4 e 5). O lucro operacional ou receita líquida foi positiva a partir do $2^{\circ}$ ano, ou seja, R\$ 2.309,00.ha-1 (AGRIANUAL, 2010). 
TABELA 1 - Caracterização dos sistemas produtivos de bananeiras fertirrigadas com diferentes doses de $\mathrm{K}_{2} \mathrm{O}$, cultivar Willians, por hectare. Palmital-SP. 2009.

*MP = mudas micropropagadas. Obs: Espaçamento: 2,0 X 2,5 m.

TABELA 2 - Estimativa do custo de produção de bananeiras em sistema de manejo fertirrigado, cultivar Willians, na ausência de $\mathrm{K}_{2} \mathrm{O}$, por hectare, por ano, na região do Médio Paranapanema, São Paulo. 2009. (em R\$ de outubro de 2009).

\begin{tabular}{|c|c|c|c|c|}
\hline \multirow{2}{*}{ Especificações } & \multicolumn{4}{|c|}{ Manejo Fertirrigado 0 kg Ko. O.ha ${ }^{-1}$ ano $^{-1}$} \\
\hline & Formação & $\mathbf{1}^{\circ}$ ciclo & $2^{\circ}$ ciclo & $3^{\circ}$ ciclo \\
\hline \multicolumn{5}{|l|}{ A. Operações Mecanizadas } \\
\hline Preparo da área & 358,00 & - & - & - \\
\hline Implantação & 176,00 & - & - & - \\
\hline Tratos culturais & 205,00 & 348,00 & 397,00 & 397,00 \\
\hline Colheita & - & 482,00 & 482,00 & 482,00 \\
\hline Implantação e manejo sistema da irrigação & 51,00 & - & - & - \\
\hline Subtotal A & 790,00 & 830,00 & $\mathbf{8 7 9 , 0 0}$ & 879,00 \\
\hline \multicolumn{5}{|l|}{ B. Operações Manuais } \\
\hline Preparo da área & 33,00 & - & - & - \\
\hline Implantação & 365,00 & - & - & - \\
\hline Tratos culturais & 425,00 & 849,00 & 939,00 & 939,00 \\
\hline Colheita & - & 526,00 & 638,00 & 638,00 \\
\hline Implantação e manejo sistema da irrigação & 230,00 & 108,00 & 108,00 & 108,00 \\
\hline Subtotal B & $1.053,00$ & $1.483,00$ & $1.685,00$ & $1.685,00$ \\
\hline \multicolumn{5}{|l|}{ C. Insumos } \\
\hline Mudas & $3.780,00$ & - & - & - \\
\hline Corretivo & 150,00 & & & \\
\hline Fertilizantes & $1.415,00$ & $1.190,00$ & $1.190,00$ & $1.190,00$ \\
\hline Defensivos & $1.145,00$ & $1.050,00$ & $1.050,00$ & $1.050,00$ \\
\hline Sacos plásticos & - & 300,00 & 350,00 & 350,00 \\
\hline Equipamentos de irrigação e manejo & $5.200,00$ & 520,00 & 520,00 & 520,00 \\
\hline Subtotal C & $11.690,00$ & $3.060,00$ & $3.110,00$ & $3.110,00$ \\
\hline Custo Op. Efetivo (COE) & $13.533,00$ & $5.373,00$ & $5.674,00$ & $5.674,00$ \\
\hline Depreciação máquinas e implementos & 237,00 & 249,00 & 264,00 & 264,00 \\
\hline Encargos sociais diretos & 347,00 & 489,00 & 556,00 & 556,00 \\
\hline Assistência técnica & 271,00 & 107,00 & 113,00 & 113,00 \\
\hline Encargos financeiros & 592,00 & 235,00 & 248,00 & 248,00 \\
\hline CESSR & - & 256,00 & 302,00 & 312,00 \\
\hline Custo Op. Total (COT) & $14.980,00$ & $6.710,00$ & $7.158,00$ & $7.168,00$ \\
\hline COT Acumulado & $14.980,00$ & $21.690,00$ & $28.848,00$ & $36.015,00$ \\
\hline Produtividade $(\mathrm{kg} / \mathrm{ha})$ & & $30.900,00$ & $36.500,00$ & $37.700,00$ \\
\hline Custo produção (R\$/kg) & - & $\mathbf{0 , 3 8}$ & $\mathbf{0 , 3 3}$ & $\mathbf{0 , 3 2}$ \\
\hline Custo caixa (R\$/cx.)* & - & 8,00 & 7,00 & 7,00 \\
\hline Preço esperado ( $\mathrm{R} \$ / \mathrm{cx})$ & & 8,00 & 8,00 & 8,00 \\
\hline Preço esperado $(\mathrm{R} \$ / \mathrm{kg})$ & - & 0,36 & 0,36 & 0,36 \\
\hline Receita Bruta (R\$/ha) & - & $11.124,00$ & $13.140,00$ & $\mathbf{1 3 . 5 7 2 , 0 0}$ \\
\hline Receita Líquida (R\$/ha) & - & $(579,00)$ & 989,00 & $1.411,00$ \\
\hline Índice Lucratividade (\%) & - & $(5,0)$ & 8,0 & $\mathbf{1 0 , 0}$ \\
\hline Rec. B. Acumulada (R\$/ha) & $(14.795,00)$ & $(10.566,00)$ & $(4.584,00)$ & $1.821,00$ \\
\hline
\end{tabular}

Obs: Caixa de $22 \mathrm{~kg}$. 
TABELA 3 - Estimativa do custo de produção de bananeiras em sistema de manejo fertirrigado, cultivar Willians, dose de $300 \mathrm{~kg}$ de $\mathrm{K}_{2} \mathrm{O}$, por hectare, por ano, na região do Médio Paranapanema, São Paulo. 2009. (em R\$ de outubro de 2009)

\begin{tabular}{|c|c|c|c|c|}
\hline \multirow[t]{2}{*}{ Especificações } & \multicolumn{4}{|c|}{$\begin{array}{l}\text { Manejo Fertirrigado } \\
300 \mathrm{~kg} \mathrm{~K}_{2} \mathrm{O} . \mathrm{ha}^{-1} . \text { ano }^{-1}\end{array}$} \\
\hline & Formação & $\mathbf{1}^{0}$ ciclo & $2^{\circ}$ ciclo & $3^{0}$ ciclo \\
\hline \multicolumn{5}{|l|}{ A. Operações Mecanizadas } \\
\hline Preparo da área & 358,00 & - & - & - \\
\hline Implantação & 176,00 & - & - & - \\
\hline Tratos culturais & 205,00 & 348,00 & 397,00 & 397,00 \\
\hline Colheita & - & 482,00 & 482,00 & 482,00 \\
\hline Implantação e manejo sistema da irrigação & 51,00 & - & - & . \\
\hline Subtotal A & 790,00 & $\mathbf{8 3 0 , 0 0}$ & 879,00 & 879,00 \\
\hline \multicolumn{5}{|l|}{ B. Operações Manuais } \\
\hline Preparo da área & 33,00 & - & - & - \\
\hline Implantação & 365,00 & - & - & - \\
\hline Tratos culturais & 425,00 & 849,00 & 939,00 & 939,00 \\
\hline Colheita & & 526,00 & 638,00 & 638,00 \\
\hline Implantação e manejo sistema da irrigação & 230,00 & 108,00 & 108,00 & 108,00 \\
\hline Subtotal B & $1.053,00$ & $1.483,00$ & $1.685,00$ & $1.685,00$ \\
\hline \multicolumn{5}{|l|}{ C. Insumos } \\
\hline Mudas & $3.780,00$ & - & - & - \\
\hline Corretivo & 150,00 & & & \\
\hline Fertilizantes & $2.120,00$ & $1.890,00$ & $1.890,00$ & $1.890,00$ \\
\hline Defensivos & $1.145,00$ & $1.050,00$ & $1.050,00$ & $1.050,00$ \\
\hline Sacos plásticos & - & 300,00 & 350,00 & 350,00 \\
\hline Equipamentos de irrigação e manejo & $5.200,00$ & 520,00 & 520,00 & 520,00 \\
\hline Subtotal C & $12.395,00$ & $3.760,00$ & $3.810,00$ & $3.810,00$ \\
\hline Custo Op. Efetivo (COE) & $14.238,00$ & $6.073,00$ & $6.374,00$ & $6.374,00$ \\
\hline Depreciação máquinas e implementos & 237,00 & 249,00 & 264,00 & 264,00 \\
\hline Encargos sociais diretos & 347,00 & 489,00 & 556,00 & 556,00 \\
\hline Assistência técnica & 285,00 & 121,00 & 127,00 & 127,00 \\
\hline Encargos financeiros & 623,00 & 266,00 & 279,00 & 279,00 \\
\hline CESSR & - & 322,00 & 389,00 & 428,00 \\
\hline Custo Op. Total (COT) & $15.730,00$ & $7.521,00$ & $7.989,00$ & $8.028,00$ \\
\hline COT Acumulado & $15.730,00$ & $23.251,00$ & $31.240,00$ & $39.268,00$ \\
\hline Produtividade (kg/ha) & & $38.900,00$ & $47.000,00$ & $51.700,00$ \\
\hline Custo produção (R\$/kg) & - & $\mathbf{0 , 3 3}$ & $\mathbf{0 , 2 8}$ & 0,26 \\
\hline Custo caixa (R\$/cx.)* & - & 8,00 & 7,00 & 6,00 \\
\hline Preço esperado (R\$/cx) & & 8,00 & 8,00 & 8,00 \\
\hline Preço esperado $(\mathrm{R} \$ / \mathrm{kg})$ & - & 0,36 & 0,36 & 0,36 \\
\hline Receita Bruta (R\$/ha) & - & $14.004,00$ & $16.920,00$ & $18.612,00$ \\
\hline Receita Líquida (R\$/ha) & - & $1.240,00$ & $3.687,00$ & $5.340,00$ \\
\hline Índice Lucratividade (\%) & - & $\mathbf{9 , 0}$ & 22,0 & 29,0 \\
\hline Rec. B. Acumulada (R\$/ha) & $(15.730,00)$ & $(9.247,00)$ & $(316,00)$ & $10.268,00$ \\
\hline
\end{tabular}

Obs: Caixa de $22 \mathrm{~kg}$. 
TABELA 4 - Estimativa do custo de produção de bananeiras em sistema de manejo fertirrigado, cultivar Willians, dose de $600 \mathrm{~kg}$ de $\mathrm{K}_{2} \mathrm{O}$, por hectare, por ano, na região do Médio Paranapanema, São Paulo. 2009.

(em R \$ de outubro de 2009)

\begin{tabular}{|c|c|c|c|c|}
\hline \multirow[t]{2}{*}{ Especificações } & \multicolumn{4}{|c|}{$\begin{array}{l}\text { Manejo Fertirrigado } \\
600 \mathrm{~kg} \mathrm{~K}_{2} \mathrm{O}_{\text {.ha }}^{-1} \text {.ano }^{-1}\end{array}$} \\
\hline & Formação & $\mathbf{1}^{0}$ ciclo & $2^{\circ}$ ciclo & $3^{\circ}$ ciclo \\
\hline \multicolumn{5}{|l|}{ A. Operações Mecanizadas } \\
\hline Preparo da área & 358,00 & - & - & - \\
\hline Implantação & 176,00 & - & - & - \\
\hline Tratos culturais & 205,00 & 348,00 & 397,00 & 397,00 \\
\hline Colheita & - & 482,00 & 482,00 & 482,00 \\
\hline Implantação e manejo sistema da irrigação & 51,00 & - & - & - \\
\hline Subtotal A & 790,00 & 830,00 & 879,00 & 879,00 \\
\hline \multicolumn{5}{|l|}{ B. Operações Manuais } \\
\hline Preparo da área & 33,00 & - & - & - \\
\hline Implantação & 365,00 & - & - & - \\
\hline Tratos culturais & 425,00 & 849,00 & 939,00 & 939,00 \\
\hline Colheita & & 526,00 & 638,00 & 638,00 \\
\hline Implantação e manejo sistema da irrigação & 230,00 & 108,00 & 108,00 & 108,00 \\
\hline Subtotal B & $1.053,00$ & $1.483,00$ & $1.685,00$ & $1.685,00$ \\
\hline \multicolumn{5}{|l|}{ C. Insumos } \\
\hline Mudas & $3.780,00$ & - & - & - \\
\hline Corretivo & 150,00 & & & \\
\hline Fertilizantes & $2.824,00$ & $2.600,00$ & $2.600,00$ & $2.600,00$ \\
\hline Defensivos & $1.145,00$ & $1.050,00$ & $1.050,00$ & $1.050,00$ \\
\hline Sacos plásticos & - & 300,00 & 350,00 & 350,00 \\
\hline Equipamentos de irrigação e manejo & $5.200,00$ & 520,00 & 520,00 & 520,00 \\
\hline Subtotal C & $13.099,00$ & $4.470,00$ & $4.520,00$ & $4.520,00$ \\
\hline Custo Op. Efetivo (COE) & $14.942,00$ & $6.783,00$ & $7.084,00$ & $7.084,00$ \\
\hline Depreciação máquinas e implementos & 237,00 & 249,00 & 264,00 & 264,00 \\
\hline Encargos sociais diretos & 347,00 & 489,00 & 556,00 & 556,00 \\
\hline Assistência técnica & 299,00 & 136,00 & 142,00 & 142,00 \\
\hline Encargos financeiros & 654,00 & 297,00 & 310,00 & 310,00 \\
\hline CESSR & - & 367,00 & 447,00 & 493,00 \\
\hline Custo Op. Total (COT) & $16.479,00$ & $8.321,00$ & $8.802,00$ & $8.848,00$ \\
\hline COT Acumulado & $16.479,00$ & $24.800,00$ & $33.602,00$ & $42.450,00$ \\
\hline Produtividade (kg/ha) & & $44.300,00$ & $54.000,00$ & $59.500,00$ \\
\hline Custo produção (R\$/kg) & - & $\mathbf{0 , 3 1}$ & 0,26 & 0,24 \\
\hline Custo caixa (R\$/cx.)* & - & 7,00 & 6,00 & 5,00 \\
\hline Preço esperado (R $\$$ cx $)$ & & 8,00 & 8,00 & 8,00 \\
\hline Preço esperado ( $\mathrm{R} \$ / \mathrm{kg})$ & - & 0,36 & 0,36 & 0,36 \\
\hline Receita Bruta (R\$/ha) & - & $15.948,00$ & $19.440,00$ & $21.420,00$ \\
\hline Receita Líquida (R\$/ha) & - & $2.134,00$ & $5.145,00$ & $7.079,00$ \\
\hline Índice Lucratividade (\%) & - & 13,0 & 26,0 & $\mathbf{3 3 , 0}$ \\
\hline Rec. B. Acumulada (R\$/ha) & $(16.479,00)$ & $(8.852,00)$ & $1.786,00$ & $14.358,00$ \\
\hline
\end{tabular}

Obs: Caixa de $22 \mathrm{~kg}$. 
TABELA 5 - Estimativa do custo de produção de bananeiras em sistema de manejo fertirrigado, cultivar Willians, dose de $900 \mathrm{~kg}$ de $\mathrm{K}_{2} \mathrm{O}$, por hectare, por ano, na região do Médio Paranapanema, São Paulo. 2009. (em R\$ de outubro de 2009)

\begin{tabular}{|c|c|c|c|c|}
\hline \multirow[t]{2}{*}{ Especificações } & \multicolumn{4}{|c|}{$\begin{array}{l}\text { Manejo Fertirrigado } \\
900 \mathrm{~kg} \mathrm{~K} \mathrm{O}_{2} \cdot \mathrm{ha}^{-1} \cdot \text { ano }^{-1}\end{array}$} \\
\hline & Formação & $\mathbf{1}^{0}$ ciclo & $2^{\circ}$ ciclo & $3^{\circ}$ ciclo \\
\hline \multicolumn{5}{|l|}{ A. Operações Mecanizadas } \\
\hline Preparo da área & 358,00 & - & - & - \\
\hline Implantação & 176,00 & - & - & - \\
\hline Tratos culturais & 205,00 & 348,00 & 397,00 & 397,00 \\
\hline Colheita & - & 482,00 & 482,00 & 482,00 \\
\hline Implantação e manejo sistema da irrigação & 51,00 & - & - & - \\
\hline Subtotal A & 790,00 & 830,00 & 879,00 & 879,00 \\
\hline \multicolumn{5}{|l|}{ B. Operações Manuais } \\
\hline Preparo da área & 33,00 & - & - & - \\
\hline Implantação & 365,00 & 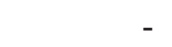 & - & \\
\hline Tratos culturais & 425,00 & 849,00 & 939,00 & 939,00 \\
\hline Colheita & - & 526,00 & 638,00 & 638,00 \\
\hline Implantação e manejo sistema da irrigação & 230,00 & 108,00 & 108,00 & 108,00 \\
\hline Subtotal B & $1.053,00$ & $1.483,00$ & $1.685,00$ & $1.685,00$ \\
\hline \multicolumn{5}{|l|}{ C. Insumos } \\
\hline Mudas & $3.780,00$ & - & - & - \\
\hline Corretivo & 150,00 & & & \\
\hline Fertilizantes & $3.340,00$ & $3.130,00$ & $3.130,00$ & $3.130,00$ \\
\hline Defensivos & $1.145,00$ & $1.050,00$ & $1.050,00$ & $1.050,00$ \\
\hline Sacos plásticos & - & 300,00 & 350,00 & 350,00 \\
\hline Equipamentos de irrigação e manejo & $5.200,00$ & 520,00 & 520,00 & 520,00 \\
\hline Subtotal C & $13.615,00$ & $5.000,00$ & $5.050,00$ & $5.050,00$ \\
\hline Custo Op. Efetivo (COE) & $15.458,00$ & $7.313,00$ & $7.614,00$ & $7.614,00$ \\
\hline Depreciação máquinas e implementos & 185,00 & 238,00 & 252,00 & 252,00 \\
\hline Encargos sociais diretos & 368,00 & 490,00 & 506,00 & 506,00 \\
\hline Assistência técnica & 273,00 & 123,00 & 126,00 & 126,00 \\
\hline Encargos financeiros & 597,00 & 269,00 & 275,00 & 275,00 \\
\hline CESSR & - & 276,00 & 326,00 & 348,00 \\
\hline Custo Op. Total (COT) & $16.880,00$ & $8.709,00$ & $9.098,00$ & $9.120,00$ \\
\hline COT Acumulado & $16.880,00$ & $25.590,00$ & $34.688,00$ & $43.808,00$ \\
\hline Produtividade (kg/ha) & & $47.800,00$ & $57.000,00$ & $62.500,00$ \\
\hline Custo produção (R\$/kg) & - & $\mathbf{0 , 3 0}$ & 0,26 & 0,24 \\
\hline Custo caixa (R\$/cx.)* & - & 7,00 & 6,00 & 5,00 \\
\hline Preço esperado (R\$/cx) & & 8,00 & 8,00 & 8,00 \\
\hline Preço esperado $(\mathrm{R} \$ / \mathrm{kg})$ & - & 0,36 & 0,36 & 0,36 \\
\hline Receita Bruta (R\$/ha) & - & $17.208,00$ & $20.520,00$ & $22.500,00$ \\
\hline Receita Líquida (R\$/ha) & - & $2.872,00$ & $5.795,00$ & $7.753,00$ \\
\hline Índice Lucratividade (\%) & - & 17,0 & 28,0 & $\mathbf{3 4 , 0}$ \\
\hline Rec. B. Acumulada (R\$/ha) & $(16.880,00)$ & $(8.382,00)$ & $3.041,00$ & $16.420,00$ \\
\hline
\end{tabular}

Obs: Caixa de $22 \mathrm{~kg}$. 


\section{CONCLUSÃO}

1-A utilização de $900 \mathrm{~kg}$ de $\mathrm{K}_{2} \mathrm{O} \cdot \mathrm{ha}^{-1} \cdot \mathrm{ano}^{-1}$ proporciona valores de Custo Operacional Total maiores; entretanto, com custo por caixa produzida menor, quando comparados com as demais doses de potássio avaliadas.

2-A produtividade média é superior quando aplicada a maior dose de potássio $\left(900 \mathrm{~kg}\right.$ de $\mathrm{K}_{2} \mathrm{O}$. $\mathrm{ha}^{-1}$.ano $\left.\mathrm{s}^{-1}\right)$, demonstrando que a cultura responde favoravelmente ao uso desse nutriente.

3-O retorno do investimento (receita bruta acumulada) ocorre a partir do $2^{\circ}$ ciclo, nos tratamentos onde foram aplicados 600 e $900 \mathrm{~kg}$ de $\mathrm{K}_{2} \mathrm{O} \cdot \mathrm{ha}^{-1}$. $\mathrm{ano}^{-1}$. Nos demais tratamentos, somente no último ciclo esse índice é positivo.

4-O uso do potássio, na dose de $900 \mathrm{~kg}$ de $\mathrm{K}_{2} \mathrm{O} \mathrm{ha}^{-1} \cdot$ ano $^{-1}$, aplicado através de sistema de fertirrigação, pode ser recomendado para a bananicultura, cultivar Willians, na região do Médio Paranapanema, Estado de São Paulo.

\section{REFERÊNCIAS}

AGRIANUAL 2009: anuário da agricultura brasileira. São Paulo: FNP, 2009. p.188-200.

AGRIANUAL 2010: anuário da agricultura brasileira. São Paulo: FNP, 2010. p.192-204.

ARAÚJO, J.L.P.; CORREIA, R.C.; ARAÚJO, E.P. Análise dos custos de produção e rentabilidade da cultura da banana na região do Vale do Submédio São Francisco. In: ENCONTRO SOBER REGIONAL NORDESTE, 3., 2008, Mossoró. Fruticultura e bioenergia: estratégias de desenvolvimento para o Nordeste... Mossoró: UFRN/SOBER, 2008. CDROM.

BORGES, A.L.; COSTA, E.L. Requerimentos de nutrientes para fertirrigação - banana. In: BORGES, A.L.; COELHO, E.F.; TRINDADDE, A.V (Org.). Fertirrigação em fruteiras tropicais. Cruz das Almas: Embrapa Mandioca e Fruticultura, 2002. p.77-84.
BORGES, A.L.; OLIVEIRA, A.M.G. Nutrição, calagem e adubação. In: CORDEIRO, Z.J.M. Banana produção: aspectos técnicos. 2.ed. Brasília: Embrapa, 2000. p.47-59. (Frutas do Brasil, 8)

CAMARGO, M.B.P.; PEDRO JUNIOR, M.J.; ALFONSI, R.R.; ORTOLANI, A.A.; BRUNINI, O. Probabilidade de ocorrência de temperaturas mínimas absolutas mensais e anual no Estado de São Paulo. Bragantia, Campinas, v.52, n.2, p.161-168, 1993.

DAMATTO JÚNIOR, E.R.; BOAS, R.L.V.; LEONEL, S.; FERNANDES, D.M. Avaliação nutricional em folhas de bananeira "Prata-Anã" adubada com composto orgânico. Revista Brasileira de Fruticultura, Jaboticabal, v.28, n.1, p.109-112, 2006.

FREITAS, W.S.; RAMOS, M.M.; COSTA, S.L. Demanda de irrigação da cultura da banana na bacia do Rio São Francisco. Revista Brasileira de Engenharia Agrícola e Ambiental, Campina Grande, v.12, n.4. p.343-349, 2008.

FURLANETO, F.P.B.; MARTINS, A.N.; CAMOLESI, M.R.; ESPERANCINI, M.S.T. Análise econômica de sistemas de produção de banana (Musa sp.), cv. Grande Naine, na região do Médio Paranapanema, Estado de São Paulo. Científica, Jaboticabal, v.35, n.2, p.188-195, 2007a.

FURLANETO, F.P.B.; MARTINS, A.N.; ESPERANCINI, M.S.T. Análise econômica da bananicultura, cultivares do subgrupo Cavendish, na região do Médio Paranapanema, Estado de São Paulo. Informações Econômicas, São Paulo, v.37, n.2, p.22-29, $2007 \mathrm{~b}$.

GUERRA, A.G.; ZANINI, J.R.; NATALE, W.; PAVANI, L.C. Frequência da fertirrigação de bananeira Prata-Anã com nitrogênio e potássio aplicados via fertirrigação. Engenharia Agrícola, Jaboticabal, v.24, n.1, p.80-88, 2004.

MAHALAKSHMI, M.; KUMAR, N.; SOORIANATHASUNDARAM, K. Effect of fertirrigation and irrigation on the yield of hight-density plantations of cv. 'Robusta'. InfoMusa, Montpellier, v.12, n.1, p.42-44, 2003.

MARTIN, N.B.; SERRA, R.; OLIVEIRA, M.D.M.O.; ÂNGELO, J.A.; OKAWA, H. Sistema integrado de custos agropecuários - CUSTAGRI. Informações Econômicas, São Paulo, v.28, n.1, p.7-28, 1998. 
MATSUNAGA, M.; BEMELMANS, P.F.; TOLEDO, P.E.N.; DULLEY, R.D.; OKAWA, H.; PERSO, I.N. Metodologia de custo de produção utilizada pelo IEA. Agricultura em São Paulo, São Paulo, v.23, n.1, p.123-139, 1976.

MELO, A.S.; SILVA JUNIOR, C.D.; FERNANDES, P.D.; SOBRA, L.F.; BRITO, E.B.; DANTAS, D.M. Alterações das características fisiológicas da bananeira sob condições de fertirrigação. Ciencia Rural, Santa Maria, v.39, n.3, p.733-741, 2009.

OLIVEIRA, S.L.; BORGES, A.L.; COELHO, E.F.; COELHO FILHO, M.A.; SILVA, J.T. Uso da irrigação e da fertirrigação na produção integrada de banana no norte de Minas Gerais. Cruz das Almas: Cruz das Almas, 2005. 7p. (Circular Técnica, 77).

PINTO, J.M.; FARIA, C.M.B.; SILVA, D.J.; FEITOSA FILHO, J.C. Doses de nitrogênio e potássio aplicadas via fertirrigação em bananeira. Irriga, Botucatu, v.10, n.1, p.46-52, 2005.

PRADO, H.; MENK, J.R.F.; TREMOCOLDI, W.A.; JORGE, J.A. Levantamento pedológico do Polo Regional de Desenvolvimento Tecnológico dos Agronegócios do Médio Paranapanema, Assis-SP. Campinas: Instituto Agronômico, 2003. 19p. (Série Pesquisa APTA, Boletim Científico, 07).

PRELA-PANTANO, A.; ROLIM, G.S.; CAMARGO, M.B.P. Probabilidade de ocorrência de temperaturas mínimas menores que $5^{\circ} \mathrm{C}$ na região do Médio Paranapanema. Bragantia, Campinas, v. 68, n. 1, p. 279-284. 2009.
ROLIM, G.S.; CAMARGO, M.B.P.; LANIA, D.G.; MORAES, J.F.L. Classificação Climática de Köeppen e de Thornthwaite e sua aplicabilidade na determinação de Zonas Agroclimáticas para o Estado de São Paulo. Bragantia, Campinas, v.66, n.4, p.711-720, 2007.

SANTANA, M.A.; ALMEIDA, C.O.; SOUZA, J.S. Custos e Rentabilidade. In: BORGES, A.L.; SOUZA, L.S. (Org.). O Cultivo da bananeira. Cruz das Almas: Embrapa Mandioca e Fruticultura, 2004. p.256-262.

SATHIAMOORTHY, S.; JEYABASKARAN, K.J. Potassium management of banana. In: WORKSHOP: POTASSIUM AND WATER MANAGEMENT IN WEST ASIA AND NORTH AFRICA, 2001, Amman: IPI/NARCTT, 2001. Disponível em: $<$ http://musalit.inibap.org/>. Acesso em: 01 out. 2009.

TEIXEIRA, L.A.J.; ZAMBROSI, F.C.B.; BETTIOL NETO, J.E. Avaliação do estado nutricional de bananeiras do subgrupo Cavendish no Estado de São Paulo: normas DRIS e níveis críticos de nutrientes. Revista Brasileira de Fruticultura, Jaboticabal, v.29, n.3, p.613-620, 2007.

ZONETTI, P.C.; TARSITANO, M.A.A.; SANTOS, P.C.; SILVA, S.C.; PETINARI, R.A. Análise de custo de produção e lucratividade de bananeira ' Nanicão Jangada' sob duas densidades de cultivo em Ilha Solteira - SP. Revista Brasileira de Fruticultura, Jaboticabal, v.24, n.2, p. 406-410, 2002. 